\title{
Retraction Note to: The role of TGFß1 stimulating ROCK I signal pathway to reorganize actin in a rat experimental model of developmental dysplasia of the hip
}

\author{
Xinhong Pei ${ }^{1}$ Yueqiang $\mathrm{Mo}^{1} \cdot \mathrm{Bo} \mathrm{Ning}^{2}$. \\ Zhe Yuan ${ }^{1} \cdot$ Luying Peng ${ }^{3} \cdot$ Ruixue Ma ${ }^{1}$
}

Published online: 17 August 2015

(c) Springer Science+Business Media New York 2015

Retraction Note to: Mol Cell Biochem (2014)

391:1-9

DOI 10.1007/s11010-014-1980-z

The Publisher and Editor retract this article in accordance with the recommendations of the Committee on Publication Ethics (COPE). After a thorough investigation we have strong reason to believe that the peer review process was compromised.

The online version of the original article can be found under doi:10.1007/s11010-014-1980-z.

Xinhong Pei

peizane@gmail.com

$\triangle$ Ruixue Ma

ruixuema23@hotmail.com

1 Department of Orthopaedics, Children's Hospital of Fudan University, 399 Wanyuan Road, Minhang District,

Shanghai 201102, China

2 Department of Pediatric Orthopaedics, Anhui Provincial Hospital, Hefei 230001, Anhui, China

3 Department of Molecular Genetics and Biochemistry, School of Medicine, Tongji University, Shanghai 200092, China 